\title{
Never be bored at a meeting again!

\author{
Using Liberating Structures in academic libraries for increased \\ productivity, employee engagement, and inclusion
}

$\mathbf{H}$ ow would you like to never be bored in a meeting or presentation? To be fully engaged, to know why you are there, and to have your ideas heard? There is a way for that to happen, a powerful and simple way to fully engage everyone present at a meeting, to unleash their creativity in solving problems, and to make all attendees feel their contributions are heard. The answer is "Liberating Structures," a set of 33 activities designed by Henri Lipmanowicz and Keith McCandless. ${ }^{1}$ Each of these activities, which range from taking fifteen minutes to three days, are designed to replace traditional meetings.

Meetings are a way of life at our library. A method for exchanging information, working on projects, keeping each other up to date. But as a person interested in productivity, efficiency, and employee engagement, I wanted more from our meetings. My dean wanted me to manage one of our monthly meetings, giving me the perfect chance to try out 12 Liberating Structures over the school year. Trying something entirely new is a bit scary, but I had done some Liberating Structures during a training, and nothing terrible happened.

Actually, good stuff happened: engaged participants, solid outcomes, and not boring. After using Liberating Structures for our library faculty meetings, my colleagues came up to me to tell me how much they enjoyed them.
Often I had to be a tough timekeeper, and stop very engaged participants in order to stay within my 30 minutes. During the year of piloting Liberating Structures, the dean and department heads gave me issues to work on using the structures. The outcomes of which were given to the prompter and used to move their project forward.

In Liberating Structures, Lipmanowicz and McCandless examined traditional meetings and broke them down into five types or "The Big Five."

1. The Status Report

2. The Brainstorm

3. The Open Discussion

4. The Managed Discussion

5. The Presentation

The authors found that each of these meeting types offered either too much control or too little control. Presentations, for instance, suffered from too much control via the moderator, while brainstorms were too loosely controlled. Each of these meeting types, methods for which people interact with each other, are what the authors call intangible microstructures. These intangible microstructures organize how we interact in a

Mark Bieraugel is business librarian at California Polytechnic State University, email: mbieraug@calpoly. edu

(ㄷ) 2017 Mark Bieraugel 
meeting. They both enable us to interact and constrain such interactions. The five meeting types have some terrible downsides, including disengaged participants, unequal power among members, dominating personalities, and wandering attention. For certain meeting types, such as presentations, a dynamic and charismatic speaker is required to fully command the attention in the room. All these aspects point to a need for an alternate method of interacting with each other at work.

But you need some amount of control when you have small or large groups of people interacting with each other; otherwise you have chaos. Liberating Structures activities inject the right amount of control into that human interaction, while allowing participants to be engaged and included in the process and outcome. Liberating Structures are designed to break down the power structures found in traditional meetings, to flatten the organization, and to allow for participation from all levels of your organization. All Liberating Structures include a "structuring invitation," question, challenge, or problem posed to the attendees. These might be as specific as "What are the next steps on this project?" or more general questions, such as "What is the biggest challenge you bring to this meeting?"

But why change? Why do something new and potentially risk looking foolish? Because organizations need employees that are engaged at work and feel included in the decisions made. Libraries face challenges that require solutions and ideas from across the enterprise, not just from a select few or from top tier management.

By switching out the Big Five meeting types with an appropriate liberating structure, you can improve the overall performance of your library. This improvement comes from tapping all attendee ideas and collaborating to help solve problems facing your institution. Liberating Structures build in the ability for all present at a meeting to feel they can participate in solving a problem, generate solutions, identify issues, all safely, and sometimes anonymously. Liberating Structures alter the power dynamics, mitigating dominant personalities who can intimidate others.

Liberating Structures provide fresh, easyto-use activities for dynamic, safe, and effective interactions during meetings. Liberating Structures are unlike other process improvement systems or productivity boosters as there is no need for major work to implement a new system of interacting. All you do is switch out a meeting type of one of the 33 Liberating Structures. ${ }^{2}$

All meeting types have unwritten rules for attendees and facilitators. For Liberating Structures, the rules are written down and divided into five components:

- The invitation-What we are here to do today at the meeting? What we want to accomplish? What is our objective?

- Space arrangement and suppliesHow are the tables and chairs arranged? Is there a white board? How are people seated? What supplies are needed? For Liberating Structures, the space is often configured differently from traditional meetings.

- Defined roles and actions-Who at the meeting can contribute? When can they contribute? Liberating Structures build in contributions for all present at the meeting.

- Group configuration-Are you one group, small groups, duos, or trios? Can the configuration change during the meeting? Liberating Structures sometimes have numerous configurations throughout a meeting.

- Time allotment and sequence of events - In a meeting, this would be an agenda, for Liberating Structures this is a set of timed interactions with attendees.

This may seem overly complex, but a whole set of instructions for a single Liberating Structure fits on one page or less.

Deciding which of the Liberating Structures' 33 activities to choose, how to introduce the structures, and wondering if it will work can be a bit overwhelming at first. Let me walk you through what I did to determine whether Liberating Structures would work in my library. 
As I mentioned earlier, I took over a monthly meeting comprised of faculty librarians and library management. The first half hour of the meeting had a traditional microstructure of the "status report," where each person was given two minutes to report on their recent work. As facilitator, my job was keeping everyone at their designated two minutes to fit into the 30-minute time slot. This type of meeting was less engaging for the 14 people listening to each person's report. Before I learned about Liberating Structures, I didn't have an alternative for how people could interact effectively in that half hour.

After I learned about Liberating Structures at a workshop I was convinced I needed to swap out the status report for a Liberating Structure. I decided to use the meeting to try out a different Liberating Structure for each meeting.

Each month I read the structure for that month, wrote step-by-step directions (since the book and website ones can be confusing) and some months printed out directions for attendees, including the "structuring invitation" to help participants.

What I learned is that you have nothing to fear about using the structures. They don't require charisma or dynamic presentation skills, but rather require very little from the meeting facilitator. The hardest thing is time keeping, as the participants are so engaged that they want to keep discussing and working on their topic at hand. This engagement lead to very productive meetings.

My colleagues were very receptive to the Liberating Structures, and willing to try something new. Key to their openness was that all of the structures have clear outcomes, a real boon for meetings. I was out for one of the monthly meetings, and a colleague was able to seamlessly take over facilitating the meeting using a Liberating Structure. It was amazing how much we could accomplish in 30 minutes using Liberating Structures, and everyone participated, which never happens during our regular meetings.

After using Liberating Structures for a few meetings, a colleague asked me to serve as a consultant for an upcoming conference he was organizing. He wanted to use a Liberating Structure during the conference as an icebreaker exercise at the beginning of the conference. Together we came up with an appropriate structure, and modified the outcome to work with the conference needs. Using a Liberating Structure truly engaged the conference participants and generated discussion content used throughout the conference.

Over this last year my most successful Liberating Structure was 1, 2, 4, ALL. I like this structure because it takes less than 15 minutes, it is easy to understand, and it works for groups of all sizes. This structure is a great way to brainstorm ideas, but with the bonus of simultaneously generating the ideas from all attendees, and without dominating personalities controlling the meeting.

As the facilitator you first invite the participants to think silently about a problem, challenge, or opportunity facing your organization. The invitation works best when it is personal. For example, "How would you redesign the reference desk for better service?" First everyone silently and individually reflects on this challenge for one minute and then writes their idea on an index card. Second, everyone gets into groups of two, and each person shares his or her idea with a partner for two minutes. Third, all get in groups of four and each person shares his or her idea with the group for four minutes, with the group noting similar or different ideas. Finally, the facilitator asks each group to report one important idea they discovered, for a total of five minutes. This activity engages everyone, gives them a chance to think and to share with individuals and smaller groups, and allows for everyone to air their ideas. These ideas can be recorded on a white board, and the moderator can take all the cards to see what ideas have been generated individually.

One Liberating Structure I am excited to use and deploy in our next meeting is "Celebrity Interview." My library recently hired a new director of external relations, a new position for us. Normally, she would give a presen-

(continues on page 431) 
Honors a distinguished academic librarian who has made outstanding contributions to Women and Gender Studies through accomplishments and service to the profession.

- University Libraries Section Outstanding Professional Development Award (sponsored by Library Juice Academy): \$1,000 award. Recognizes librarians, archivists, or curators whose contributions to providing professional development opportunities for librarians have been especially noteworthy or influential.

\section{Research awards and grants}

- ESS De Gruyter European Librarianship Study Grant (sponsored by the Walter de Gruyter Foundation for Scholarship and Research): $€ 2,500$ grant. Supports research in European studies with an emphasis on librarianship, the book trade, resource documentation, and similar information-science related topics.

\section{Publications}

- Katharine Kyes Leab and Daniel J. Leab Exhibition Catalogue Awards (spon- sored by Katharine Kyes Leab and Daniel J. Leab, American Book Prices Current): Recognizes outstanding catalogs published by American or Canadian institutions in conjunction with library exhibitions. Deadline: October 15, 2017.

- Ilene F. Rockman Instruction Publication of the Year Award (sponsored by Emerald Publishing): \$3,000 award. Recognizes an outstanding publication related to instruction in a library environment published in the last two years.

- Science and Technology Section Oberly Award for Bibliography in the Agricultural or Natural Sciences: This biennial award is given in odd-numbered years for the best English-language bibliography in the field of agriculture or a related science.

If you would like more information about the ACRL 2018 Awards Program, visit the Awards and Scholarships section of our website at www.acrl.org or contact ACRL Program Officer Chase Ollis at collis@ala.org.

We welcome your nominations and look forward to celebrating achievements in academic librarianship in 2018. $\boldsymbol{z}$

("Never be bored at a meeting again!," continues from page 428)

tation on her new role, activities, and goals, and then have some time for questions and answers at the end. Instead, I plan on having the new director as our "celebrity interview" at an upcoming meeting. The "celebrity" first has a 15-minute interview with the moderator with prepared questions, and has attendees watching and taking notes. The next ten minutes has the audience generate a series of questions using the Liberating Structure 1,2,4 ALL, followed by the audience generated questions posed to the "celebrity." How this differs from the presentation is that even with prepared questions during the first $15 \mathrm{~min}$ utes, there is still a liveliness that comes from an interview. The involvement in generating questions together creates a stronger connection between the speaker and the audience, and the questions are vetted by attendees, making for more interesting questions.
Liberating Structures often build time and structure for quiet, individual reflection, a commodity in short supply in meetings. The library, as a service organization, needs tools to tap the collective intelligence of staff to find local solutions to challenges and opportunities. Try a Liberating Structure at your next meeting or event, my experience tells me that you will be very pleased at how engaged the attendees are, and how much more productive your meeting will be.

\section{Notes}

1. Henri Lipmanowicz and Keith McCandless, The surprising power of liberating structures (New York: Liberating Structures Press, 2013).

2. "Liberating Structures Menu," accessed August 5, 2016, www.liberatingstructures. $\mathrm{com} / \mathrm{ls} / . \not 2$ 